\title{
Process Planning and Scheduling with WNOPPT Weighted Due-Date Assignment where Earliness, Tardiness and Due- Dates are Penalized
}

\author{
Halil İbrahim Demir ${ }^{* 1}$, Onur Canpolat ${ }^{1}$, Caner Erden ${ }^{1}$, Fuat Şimşir ${ }^{2}$ \\ ${ }^{1}$ Sakarya University, Faculty of Engineering Industrial Engineering Department, Sakarya, Turkey. \\ ${ }^{2}$ Karabuk University, Faculty of Engineering, Department of Industrial Engineering, Baliklarkayasi Mevkii 78050 Karabük
}

\begin{abstract}
Process planning, scheduling and due date assignment are three important manufacturing functions in production system in which process planning is input to scheduling processes. Because of rigid process plans, alternative plans are not used that may affect global performance improvement in a bad way. Besides, scheduling without considering process plans causes unbalanced machine loadings and leads to several bottlenecks. In the literature, there are numerous works on process planning and scheduling and works on scheduling with due date assignment. These three functions are not integrated much. According to literature, due dates are assigned without considering weights of the customer. In this study, these three functions are integrated and due dates are given according to the importance of the customers. Eight shop floors are studied. Different levels of integration of these three functions are tested and compared with each other. Two search techniques used which are genetic search and random search and results are compared with ordinary solutions. As the level of integration increased solutions became better and search techniques gave a better result than ordinary solutions and the genetic search outperformed random search.
\end{abstract}

Keywords: Process Planning, Weighted Scheduling, Weighted Due-Date Assignment, Genetic Algorithms, Random Search

\section{Erken Tamamlanma, Gecikme ve Teslim Tarihinin Cezalandırıldığı Durumda Proses Planlama ve Çizelgelemenin WNOPPT Ağırlıklı Teslim Tarihi Belirleme ile Entegrasyonu}

$\ddot{\mathbf{O z}}$

Proses planlama, çizelgeleme ve teslim tarihi belirleme üç önemli imalat fonksiyonudur. Literatüre göre proses planlama ve çizelgelemenin entegrasyonu ve teslim tarihi belirlemeli çizelgeleme üzerine çok sayıda çalışma vardır. Fakat bu üç fonksiyonun entegre edildiği çalışmalar azdır. Literatüre göre teslim tarihleri müşteri ağırlıklarını hesaba katmadan verilmektedir. Bu çalışmada üç fonksiyon entegre edilmiş ve teslim tarihleri müşteri önemi hesaba katılarak verilmiştir. Sekiz atölye çalışılmıştır. Bu üç fonksiyonun farklı entegrasyon seviyeleri test edilmiş, birbirleriyle karşılaştırılmıştır. Genetik arama ve rassal aramadan oluşan iki arama tekniği kullanılmış ve sonuçları sıradan çözümlerle karşılaştırılmıştır. Entegrasyon seviyesi arttıkça sonuçlar daha iyi olmuş, arama teknikleri sıradan çözümlere göre daha iyi sonuçlar vermiş ve genetik arama rassal aramadan üstün çıkmıştır.

Anahtar kelimeler: Proses Planlama, Ağırlıklı Çizelgeleme, Ağılıklı Teslim Tarihi Belirleme, Genetik Algoritmalar, Rassal Arama

\section{Introduction}

Process planning, scheduling and due date assignment are three important manufacturing functions and treated separately. These three functions have an effect on each other and it is better if they are treated simultaneously. In the literature, we can see numerous work on scheduling with due date assignment(Adamopoulos and Pappis, 1998; Biskup and Jahnke, 2001; Gordon et al., 2002; Gordon and Kubiak,

\footnotetext{
* Corresponding Author.

E-mail: hidemir@sakarya.edu.tr
}

$\begin{array}{ll}\text { Recieved } & : 11 \text { June. } 2018 \\ \text { Revision } & : 1 \text { Aug. } 2018 \\ \text { Accepted } & : 3 \text { Aug. } 2018\end{array}$


1998; Li et al., 2011; Panwalkar et al., 1982; Ying, 2008) and works on integrated process planning and scheduling (Amin-Naseri and Afshari, 2012; Guo et al., 2009, 2009; Leung et al., 2010; Lim and Zhang, 2004; Moon et al., 2008; Morad and Zalzala, 1999; Zhang and Mallur, 1994). But except authors of this study, there are not many works on integrating these three functions. According to this research, we tested different levels of integration and we observed that higher integration levels give better results because of improved global performance.

Only scheduling sub problem belongs to NP Hard class problems and if we integrate process planning and due date assignment, the problem becomes even more complex and belongs to NP hard problems. That's why exact solutions are only possible for very small problems. As problems get bigger it becomes practically impossible to find the exact solution to the problem. Therefore, heuristic algorithms can and should be used to find a good solution to the problem in a reasonable amount of time. In this study, according to different integration levels, some ordinary solutions are compared with the solutions of genetic search and random search. Always searches are found better than ordinary solutions and genetic search outperformed random search.

If we look at these three functions consecutively; Process planning has been defined by Society of Manufacturing Engineers as the systematic determination of the methods by which a product is to be manufactured economically and competitively. Production scheduling is a resource allocator, which considers timing information while allocating resources to the tasks (Zhang and Mallur, 1994). "The scheduling problems involving due dates are of permanent interest. In a traditional production environment, a job is expected to be completed before its due date. In a justin-time environment, a job is expected to be completed exactly at its due date" (Gordon et al., 2002).

Because of development in hardware, software and algorithms, it becomes easier to perform some tasks and to solve problems which could not be solved earlier. Recent developments in computer made it possible to prepare process plans. CAPP (Computer Aided Process Planning) is developed and it becomes easy to prepare process plans. The output of process planning is the input of scheduling so poor inputs cause many problems at shop floor. Process planners can select some desired machines repeatedly and may not select some undesired machines at all. This causes unbalanced machine loads and reduces shop floor utilization. In case of some undesired and unexpected occurrences such as machine break down, it is difficult to respond this situation, but if alternative process plans are prepared and if quality process plans are available then it becomes better and easier to schedule at shop floor level. In this case, it becomes possible to react unexpected occurrences and to get balanced machine load and higher shop floor utilization.
Since every customer may not be as important as some other customers we had better schedule important customers first. In this study weighted and unweighted dispatching rules are used. Another very important application of this study is to assign close due dates for the relatively more important customers and far due dates for less important customers. Weighted due date assignment is not treated in the literature much. Findings of this study suggest using weighted due dates assignment. We used WNOPPT (Weighted number of operation plus processing time) as due date assignment method. In this method, due dates are assigned proportionally to processing times plus a proportional amount of number of operations. Motivation in this study is to integrate three functions to improve global performance and use weighted scheduling to schedule important customer first and assign weighted due dates for important customers. Every aspect of this study contributed to overall performance.

As expected weighted tardiness is undesired but in JIT environment weighted earliness is also undesired. We also penalized weighted due dates and far due dates are penalized more. Long due dates may mean customer ill will, customer loss and price reduction. So we should not give far due dates unnecessarily and also we should keep our promises. So it is very important to give close due dates for more important customers and keep our promises. According to performance measure, it is better to give far due dates for less important customers and keep our promises. Jobs should be completed as near as given due dates.

\section{Background and Literature Survey}

As mentioned earlier there are numerous works on process planning and scheduling and on scheduling with due date assignment. Integration of these three functions is mentioned by ((Demir, H.I. et al., 2004)). In this study integration of process planning and weighted scheduling with WNOPPT due-date assignment was studied. Weighted Earliness, Tardiness and due-dates are punished. Weighted Earliness, Tardiness and due-dates are linearly punished with different proportion and proportional to time and importance of the customer. In case of earliness and tardiness, a fixed cost also added to the performance measure. Higher cost is given for tardiness compared to earliness.

If we look at works on IPPS (Integrated process planning and scheduling) we can see numerous works. If we list earlier works on IPPS, we can see following works. (Khoshnevis and Chen, 1991), (Hutchison et al., 1991), (Chen and Khoshnevis, 1993), (Zhang and Mallur, 1994), (Brandimarte, 1999), (Kim and Egbelu, 1999), (Morad and Zalzala, 1999) worked in this area up to 2000 .

If we look at more recent works, we can see following literature. (Tan and Khoshnevis, 2000), (Kim et al., 2003), (Usher, 2003), (Lim and Zhang, 2004), (Tan and Khoshnevis, 2004), (Kumar and Rajotia, 
2005), (Moon et al., 2008), (Li et al., 2010), (Leung et al., 2010), (Phanden et al., 2011) .

If we look at the literature we see that it is hard to solve integrated problems. Some solutions are only possible for small problems. For IPPS in the literature, people use genetic algorithms, evolutionary algorithms or agent based approach for integration, or they decompose problems because of the complexity of the problem. They decompose problems into loading and scheduling sub problems. They use mixed integer programming at the loading part and heuristics at the scheduling part, (Demir et al., 2015).

Scheduling with due date assignment is also extensively studied topic. But scheduling with weighted due date assignment is not mentioned much. In this study closer due dates are given to important customers and these customers are scheduled first so we gained from weighted tardiness, due dates and earliness. Relatively far due dates are given for less important customers. A state of the art review on scheduling with due date assignment is given by (Gordon et al., 2002). Conventionally tardiness is penalized and length of due date and earliness are not penalized. Due dates are given independently of the importance of the customer. In this study weighted due date assignment with WNOPPT is integrated with process planning and weighted scheduling. Due dates can be determined internally or externally. If dates are determined externally out of our control we try to meet due dates but if we can determine due dates internally we look for best due dates which are the most profitable and dates with the least cost. According to modern approach earliness and due dates are also penalized as well.

If we look at the literature we can see SMSWDDA (Single machine scheduling with due date assignment) and MMSWDDA (multiple machine scheduling with due date assignment). Most of the works try to find a common due date for the jobs but this research finds different due dates for each customer (Adamopoulos and Pappis, 1998; Biskup and Jahnke, 2001; Cheng et al., 2002; Lauff and Werner, 2004; Nearchou, 2008; Panwalkar et al., 1982).

In the literature, there is not much work done on IPPSDDA (integrated process planning, scheduling and due date assignment). (Demir, H.I. and Taskin, H., 2005) studied IPPSDDA problem in a PhD thesis. Later (Demir, H.I. et al., 2004) studied the benefit of integrating these three functions. Benefits of integrating due date assignment with IPPS is studied by (Ceven, E. and Demir, H.I., 2007) in a Master of Science thesis.

As we mentioned earlier many works are on single machine scheduling with due date assignment. Following works are in this area: (Panwalkar et al., 1982), (Gordon and Kubiak, 1998), (Biskup and Jahnke, 2001), (Cheng et al., 2002), (Ying, 2008), (Nearchou, 2008), (Xia et al., 2008), (Gordon and Strusevich, 2009), and (Li et al., 2011).

There are examples on multiple machine scheduling with due date assignment problems. (Adamopoulos and
Pappis, 1998), (Cheng and Kovalyov, 1999), and (Lauff and Werner, 2004) studied multiple machine problems.

In this research, we have multiple customers and each will have their own due date according to the importance of the customers and multiple machine job shop scheduling is integrated with due date assignment and process planning.

\section{Problem Studied}

With this research, we studied IPPSDDA (Integrated Process Planning, scheduling and due date assignment). We have alternative process plans for each job. For relatively smaller four shop floors, we have five alternative routes for each job and for larger four shop floors in order to find a solution in a reasonable amount of time we have three alternative routes. We integrated process planning with different dispatching rules and with WNOPPT weighted due date assignment rule. For the comparison purpose, we also tested RDM (Random) due date assignment rule. WNOPPT assignment rule is used to represent endogenous due date assignment and $\mathrm{RDM}$ rule is used to represent exogenous due date assignment rule.

We have eight shop floors as we mentioned earlier. For instance, first shop floor has 25 jobs and 5 machines. At the relatively smaller shop floors (SF), for example, at the first, second, third and fourth shop floors (SF1, $\mathrm{SF} 2, \mathrm{SF} 3, \mathrm{SF} 4)$, jobs have 5 alternative routes and each route has 10 operations. At the SF1 and SF2 200 iterations are applied. At the larger shop floors (SF), for instance, fifth, sixth, seventh and eighth shop floors (SF5, SF6, SF7, SF8) we have 3 alternative routes and each route has 10 operations. At the SF5 and SF6 100 iterations are applied. In every case, each operation has processing time (PT) according to the formula given in Table 2 . We produced processing times randomly and characteristics of each shop floor are given in Table 1.

Table 1. Shop floors

\begin{tabular}{lcccccccc}
\hline Shop Floor & 1 & 2 & 3 & 4 & 5 & 6 & 7 & 8 \\
\hline \# of & 5 & 10 & 15 & 20 & 25 & 30 & 35 & 40 \\
machines & & & & & & & & \\
\# of Jobs & 25 & 50 & 75 & 100 & 125 & 150 & 175 & 200 \\
\# of Routes & 5 & 5 & 5 & 5 & 3 & 3 & 3 & 3 \\
\# of op. per & 10 & 10 & 10 & 10 & 10 & 10 & 10 & 10 \\
job & & & & & & & \\
\#of iterations & 200 & 200 & 150 & 150 & 100 & 100 & 50 & 50 \\
\hline
\end{tabular}

Machines are grouped into three and first machine group (MG1) represents new modern machines and requires relatively shorter processing times. MG2 represents average machines and requires average processing times and MG3 represent old machines and requires more processing times. These are all summarized in the Table 2. For smaller shop floors if we select route 1 as the process plan then $80 \%$ modern machines are selected and processing times change according to the formula $\lfloor(10+z * 5)\rfloor$, where 
processing times assume duration with mean 10 and the standard deviation is 5 minute. $10 \%$ average machines are selected and $10 \%$ old machines are selected. If route 3 is selected then each group of machines have equal probability to be selected. For route 5 mostly classical old machines are selected. Larger shop floors have only 3 alternative routes.

Table 2. Probability of selecting machine groups and related processing times

\begin{tabular}{cccccccc}
\hline SF & MG & PT & Route 1 & Route 2 & Route 3 & Route 4 & Route 5 \\
\hline \multirow{5}{*}{$1,2,3,4$} & 1 & $\lfloor(10+\mathrm{z} * 5)\rfloor$ & 0,8 & 0,6 & 0,33 & 0,2 & 0,1 \\
& 2 & $\lfloor(12+\mathrm{z} * 6)\rfloor$ & 0,1 & 0,25 & 0,33 & 0,3 & 0,2 \\
& 3 & $\lfloor(14+\mathrm{z} * 7)\rfloor$ & 0,1 & 0,15 & 0,34 & 0,5 & 0,7 \\
$5,6,7,8$ & 1 & $\lfloor(10+\mathrm{z} * 5)\rfloor$ & 0,7 & 0,33 & 0,2 & $\mathrm{x}$ & $\mathrm{x}$ \\
& 2 & $\lfloor(12+\mathrm{z} * 6)\rfloor$ & 0,2 & 0,33 & 0,2 & $\mathrm{x}$ & $\mathrm{x}$ \\
& 3 & $\lfloor(14+\mathrm{z} * 7)\rfloor$ & 0,1 & 0,34 & 0,6 & $\mathrm{x}$ & $\mathrm{x}$ \\
\hline
\end{tabular}

We penalized due dates, earliness and tardiness according to the formulas listed below. We assumed one shift per day and total $8 * 60=480$ minutes per day.

All terms are punished linearly with different multipliers and constant in earliness and tardiness cases. Tardiness is punished more compared to earliness in terms of fixed and variable cost. All terms are multiplied by the associated weights of the customers to penalize more in case of an important customer. Due dates are punished with proportional to the length of due date times multiplied by 8 and associated weights of the customers. Earliness is punished with fixed cost 5 and proportionally 4 times of the earliness and multiplied by the weights of the customers.

Tardiness is punished with fixed cost 10 and proportionally 12 times of the tardiness and multiplied by the associated weights of the customers. Punishment functions for every job are given below where PD is a penalty for due-date, PE is a penalty for earliness and PT is a penalty for tardiness;

$$
\begin{aligned}
& P . D=\text { weight }(j) * 8 *(\text { Due-date/480 }) \\
& P . E=\text { weight }(j) *(5+4 *(E / 480)) \\
& P . T=\text { weight }(j) *(10+12 *(T / 480))
\end{aligned}
$$

\section{Solution Techniques}

We used two search techniques and ordinary solutions to compare. As directed search, we used a genetic algorithm and as undirected search, we used random search. Each solution can be explained as follows:

Ordinary Solution: Here we used initial solutions for the comparison purpose. For the genetic algorithm, we defined three population. Main population, crossover population and mutation population. Initially, randomly we produced three populations as big as main population, crossover population and mutation population. If we count best of these three populations as the initial starting main population and as the first iteration then we can say that ordinary solution is the result of the first iteration. Since we just calculated best of initial three populations that's why it took a negligible amount of time to find these results. Defined three populations are required in genetic search during the program run.

Random Search: This is undirected search and used for the comparison purpose. This search always gave better solutions than ordinary solutions. Marginal improvement in performance measure was found good at the very early iterations but sharply reduced as iteration goes on. Here we used three populations as we used in the genetic search. We used the same size of populations to be fair in comparison of random search, genetic search and ordinary solutions. At every iteration, we produced brand new randomly produced populations as big as crossover population and mutation population and selected best of last step main population, newly produced crossover population and mutation population and resulting population is the next step main population.

Genetic Algorithms: In this search, we used three populations at each iteration. Using the last main population with size ten, by applying crossover operator we produced 6 new solutions that constitute crossover population and by applying mutation operator we produced 4 new solutions that make mutation population. For the next step main population, we selected best 10 chromosomes out of 20 chromosomes of three populations.

We represented solutions as chromosomes which have $($ job size +2$)$ genes. The first gene is used for due date assignment rules and the second gene is used for dispatching rules. Remaining genes are used to represent each jobs route selected out of 5 or 3 depending on the size of the shop floor. A sample chromosome is given in Figure 1.

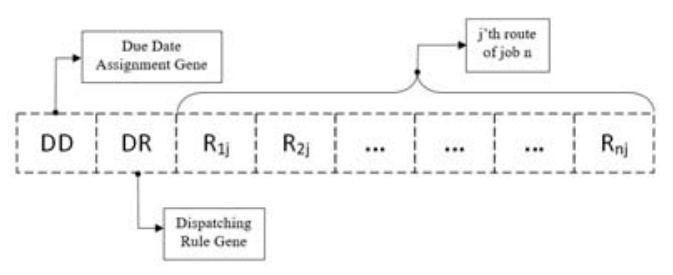

Figure 1. Sample chromosome 
Due dates were assigned using mainly two different rules. The first rule is weighted due date assignment rule WNOPPT and represents internal due date assignment and considers weight of each customer. The second rule is random RDM due date assignment rule that assigns due dates randomly which represent external due date assignment. With the multipliers, due date assignment gene takes one of 10 different values. These rules are explained in Table 3.

Table 3. Due-Date Assignment Rules

\begin{tabular}{cccc}
\hline Method & Multiplier1 & Multiplier2 & Rule no \\
\hline WNOPPT & $\mathrm{k}_{\mathrm{x}}=1,2,3$ & $\mathrm{k}_{\mathrm{y}}=1,2,3$ & $1,2,3,4,5,6,7,8,9$ \\
RDM & & & 10 \\
\hline
\end{tabular}

In order to dispatch nine different methods were used. Considering weights and different multipliers, the second gene took one of 21 different values. Dispatching rules are given and explained in Table 4.

Table 4. Dispatching Rules

\begin{tabular}{ccc}
\hline Method & Multiplier & Rule no \\
\hline WATC & $\mathrm{k}_{\mathrm{x}}=1,2,3$ & $1,2,3$ \\
ATC & $\mathrm{k}_{\mathrm{x}}=1,2,3$ & $4,5,6$ \\
WMS, MS & & 7,8 \\
WSPT, SPT & & 9,10 \\
WLPT, LPT & & 11,12 \\
WSOT, SOT & & 13,14 \\
WLOT, LOT & & 15,16 \\
WEDD, EDD & & 17,18 \\
WERD, ERD & & 19,20 \\
SIRO & & 21 \\
\hline
\end{tabular}

\section{Compared Solutions}

Service in Random Order (SIRO)- Random due assign (RDM), Ordinary Solutions (OS, Random Search (RS), Genetic Algorithms (GA)): In this combination, jobs are scheduled in random order (SIRO) and due dates are determined randomly (RDM). This is the lowest level of integration. In this case, three functions are unintegrated. Ordinary solutions, random search results and genetic search results are compared.

Weighted Scheduling (WSCH)-RDM (OS, RS, GA): Here we integrated WSCH with process plan selection but due dates are still randomly determined.

SIRO- Weighted Number of operations plus

Processing Times (WNOPPT) (OS, RS, GA): With this combination, we integrated due date assignment with process planning and as weighted due date assignment rule WNOPPT is used.

WSCH-WNOPPT (OS, RS, GA): This is the highest level of integration. Here we integrated three functions.

We selected process plans among the list and we dispatched jobs by using 21 dispatching rules and assigned due dates using WNOPPT.

We compared twelve solutions with each other to determine whether the integration of scheduling with process planning or integration of process planning with weighted due date assignment or integrating all three functions are beneficial. We compared search techniques with ordinary solutions and we tested how directed search is well compared to undirected search. Ordinary solutions are found always poor and searches are found well and directed search (GA) outperformed undirected search (RS). We presented results in the experimentation part and made a conclusion in the final part of the paper.

\section{Experimentation}

We coded problem using $\mathrm{C}++$ which performs genetic or random iterations, assign due dates and schedule jobs according to given 21 dispatching rules.

We tested eight shop floors for twelve types of solutions. We first looked at unintegrated process planning scheduling and due-date assignment as SIRO-RDM (OS, $\mathrm{RS}, \mathrm{GA}$ ). Later we integrated weighted scheduling with process planning and used random due-date assignment. At these solutions, we looked at WSCH-RDM (OS, RS, GA). After that, we tested integration of weighted due date assignment with process planning and tested SIROWNOPPT (OS, RS, GA). Finally, we integrated process planning, weighted scheduling and WNOPPT Due-date assignment and looked at the solutions SCH-WNOPPT (OS, RS, GA). Explanations of these solutions are given in section 5 .

We tested eight shop floors for twelve types of solutions. The first shop floor is small shop floor and there are 5 machines, 25 jobs with 10 operations each and each job have 5 alternative process plans. We compared twelve solutions and four of them are ordinary solutions for different levels of integration. We used results of initial populations as the ordinary solutions. Because of the limited space only for the fully integrated level, we illustrated ordinary solutions in Table 5. Four of the solutions are genetic search solutions and remaining solutions are the random search solutions.

Results of every shop floor are given in Table 5 and in Figure 2 and Figure 3. According to results, ordinary solutions are the poorest and integration found useful. As integration level increased solutions are found better. Genetic search found better than random search. 
Table 5. Comparison of Nine Types of Solutions for Eight Shop Floors

\begin{tabular}{lccc}
\hline \multicolumn{4}{c}{ Shop Floor 1 } \\
\hline & Best & Avg. & Worst \\
\hline 1-1-SIRO-RDM-random & 265,0 & 271,8 & 276,1 \\
1-1-SIRO-RDM-genetic & 241,6 & 245,4 & 248,7 \\
1-2-WSCH-RDM-random & 212,4 & 219,4 & 222,2 \\
1-2-WSCH-RDM-genetic & 216,7 & 218,2 & 218,8 \\
1-3-SIRO-WNOPPT-random & 259,4 & 265,1 & 269,0 \\
1-3-SIRO-WNOPPT-genetic & 244,8 & 248,1 & 250,0 \\
1-4-WSCH-WNOPPT-ordinary & 224,6 & 251,9 & 318,8 \\
1-4-WSCH-WNOPPT-random & 191,0 & 195,6 & 197,8 \\
1-4-WSCH-WNOPPT-genetic & 184,5 & 185,2 & 185,9 \\
\hline
\end{tabular}

\begin{tabular}{lccc}
\hline \multicolumn{4}{c}{ Shop Floor 2 } \\
\hline & Best & Avg. & Worst \\
\hline 1-1-SIRO-RDM-random & 601,5 & 607,2 & 612,7 \\
1-1-SIRO-RDM-genetic & 523,9 & 534,4 & 538,5 \\
1-2-WSCH-RDM-random & 456,0 & 474,6 & 480,4 \\
1-2-WSCH-RDM-genetic & 471,6 & 479,1 & 482,6 \\
1-3-SIRO-WNOPPT-random & 548,2 & 566,7 & 573,7 \\
1-3-SIRO-WNOPPT-genetic & 515,2 & 524,2 & 529,6 \\
1-4-WSCH-WNOPPT-ordinary & 485,8 & 640,2 & 809,5 \\
1-4-WSCH-WNOPPT-random & 448,8 & 455,9 & 459,6 \\
1-4-WSCH-WNOPPT-genetic & 419,7 & 425,1 & 427,1 \\
\hline
\end{tabular}

\begin{tabular}{lccc}
\hline \multicolumn{4}{c}{ Shop Floor 3 } \\
\hline & Best & Avg. & Worst \\
\hline 1-1-SIRO-RDM-random & 852,8 & 894,7 & 907,9 \\
1-1-SIRO-RDM-genetic & 833,5 & 840,3 & 843,8 \\
1-2-WSCH-RDM-random & 691,2 & 700,0 & 707,9 \\
1-2-WSCH-RDM-genetic & 648,9 & 649,1 & 649,4 \\
1-3-SIRO-WNOPPT-random & 838,5 & 850,7 & 855,5 \\
1-3-SIRO-WNOPPT-genetic & 780,1 & 783,1 & 784,8 \\
1-4-WSCH-WNOPPT-ordinary & 669,5 & 866,6 & 1119,2 \\
1-4-WSCH-WNOPPT-random & 622,4 & 663,2 & 672,4 \\
1-4-WSCH-WNOPPT-genetic & 597,0 & 601,7 & 603,2 \\
\hline
\end{tabular}

\begin{tabular}{lccc}
\hline \multicolumn{4}{c}{ Shop Floor 4 } \\
\hline & Best & Avg. & Worst \\
\hline 1-1-SIRO-RDM-random & 1263,6 & 1278,8 & 1292,3 \\
1-1-SIRO-RDM-genetic & 1208,7 & 1223,3 & 1228,0 \\
1-2-WSCH-RDM-random & 1002,4 & 1032,4 & 1043,3 \\
1-2-WSCH-RDM-genetic & 1077,7 & 1087,8 & 1098,1 \\
1-3-SIRO-WNOPPT-random & 1194,4 & 1212,7 & 1220,4 \\
1-3-SIRO-WNOPPT-genetic & 1143,2 & 1158,6 & 1168,9 \\
1-4-WSCH-WNOPPT-ordinary & 943,0 & 1062,3 & 1223,7 \\
1-4-WSCH-WNOPPT-random & 932,5 & 936,2 & 938,7 \\
1-4-WSCH-WNOPPT-genetic & 897,2 & 898,2 & 899,0 \\
\hline
\end{tabular}

\begin{tabular}{lccc}
\hline \multicolumn{4}{c}{ Shop Floor 5 } \\
\hline & Best & Avg. & Worst \\
\hline 1-1-SIRO-RDM-random & 1515,4 & 1554,5 & 1568,5 \\
1-1-SIRO-RDM-genetic & 1461,7 & 1476,7 & 1485,3 \\
1-2-WSCH-RDM-random & 1213,5 & 1225,4 & 1237,7 \\
1-2-WSCH-RDM-genetic & 1227,3 & 1231,3 & 1234,1 \\
1-3-SIRO-WNOPPT-random & 1463,1 & 1481,1 & 1491,4 \\
1-3-SIRO-WNOPPT-genetic & 1389,8 & 1399,3 & 1404,7 \\
1-4-WSCH-WNOPPT-ordinary & 1170,8 & 1435,1 & 1689,9 \\
1-4-WSCH-WNOPPT-random & 1082,9 & 1108,4 & 1116,2 \\
1-4-WSCH-WNOPPT-genetic & 1039,3 & 1041,0 & 1042,9 \\
\hline
\end{tabular}

\begin{tabular}{lccc}
\hline \multicolumn{4}{c}{ Shop Floor 6 } \\
\hline & Best & Avg. & Worst \\
\hline 1-1-SIRO-RDM-random & 1855,4 & 1882,0 & 1894,5 \\
1-1-SIRO-RDM-genetic & 1790,8 & 1805,4 & 1814,1 \\
1-2-WSCH-RDM-random & 1458,8 & 1512,7 & 1530,4 \\
1-2-WSCH-RDM-genetic & 1413,7 & 1414,4 & 1415,0 \\
1-3-SIRO-WNOPPT-random & 1755,0 & 1788,4 & 1800,2 \\
1-3-SIRO-WNOPPT-genetic & 1690,2 & 1698,7 & 1703,8 \\
1-4-WSCH-WNOPPT-ordinary & 1359,3 & 1542,1 & 2143,6 \\
1-4-WSCH-WNOPPT-random & 1310,4 & 1348,1 & 1364,2 \\
1-4-WSCH-WNOPPT-genetic & 1262,6 & 1265,7 & 1268,1 \\
\hline
\end{tabular}

\begin{tabular}{lccc}
\hline \multicolumn{4}{c}{ Shop Floor 7 } \\
\hline & Best & Avg. & Worst \\
\hline 1-1-SIRO-RDM-random & 2112,4 & 2149,7 & 2169,2 \\
1-1-SIRO-RDM-genetic & 2108,7 & 2117,2 & 2121,2 \\
1-2-WSCH-RDM-random & 1678,3 & 1723,0 & 1756,0 \\
1-2-WSCH-RDM-genetic & 1704,2 & 1709,5 & 1712,6 \\
1-3-SIRO-WNOPPT-random & 2004,9 & 2034,5 & 2046,7 \\
1-3-SIRO-WNOPPT-genetic & 1977,8 & 1987,3 & 1994,1 \\
1-4-WSCH-WNOPPT-ordinary & 1576,0 & 1814,3 & 2403,3 \\
1-4-WSCH-WNOPPT-random & 1519,4 & 1558,5 & 1573,2 \\
1-4-WSCH-WNOPPT-genetic & 1512,1 & 1515,5 & 1517,7 \\
\hline
\end{tabular}

\begin{tabular}{lccc}
\hline \multicolumn{4}{c}{ Shop Floor 8 } \\
\hline & Best & Avg. & Worst \\
\hline 1-1-SIRO-RDM-random & 2666,6 & 2712,8 & 2730,9 \\
1-1-SIRO-RDM-genetic & 2610,3 & 2622,1 & 2630,8 \\
1-2-WSCH-RDM-random & 2206,9 & 2227,1 & 2240,8 \\
1-2-WSCH-RDM-genetic & 2016,2 & 2023,6 & 2029,1 \\
1-3-SIRO-WNOPPT-random & 2519,6 & 2534,7 & 2552,0 \\
1-3-SIRO-WNOPPT-genetic & 2372,4 & 2389,8 & 2400,8 \\
1-4-WSCH-WNOPPT-ordinary & 1975,6 & 2267,8 & 2708,9 \\
1-4-WSCH-WNOPPT-random & 1917,7 & 1970,7 & 1999,1 \\
1-4-WSCH-WNOPPT-genetic & 1861,9 & 1870,9 & 1874,4 \\
\hline
\end{tabular}



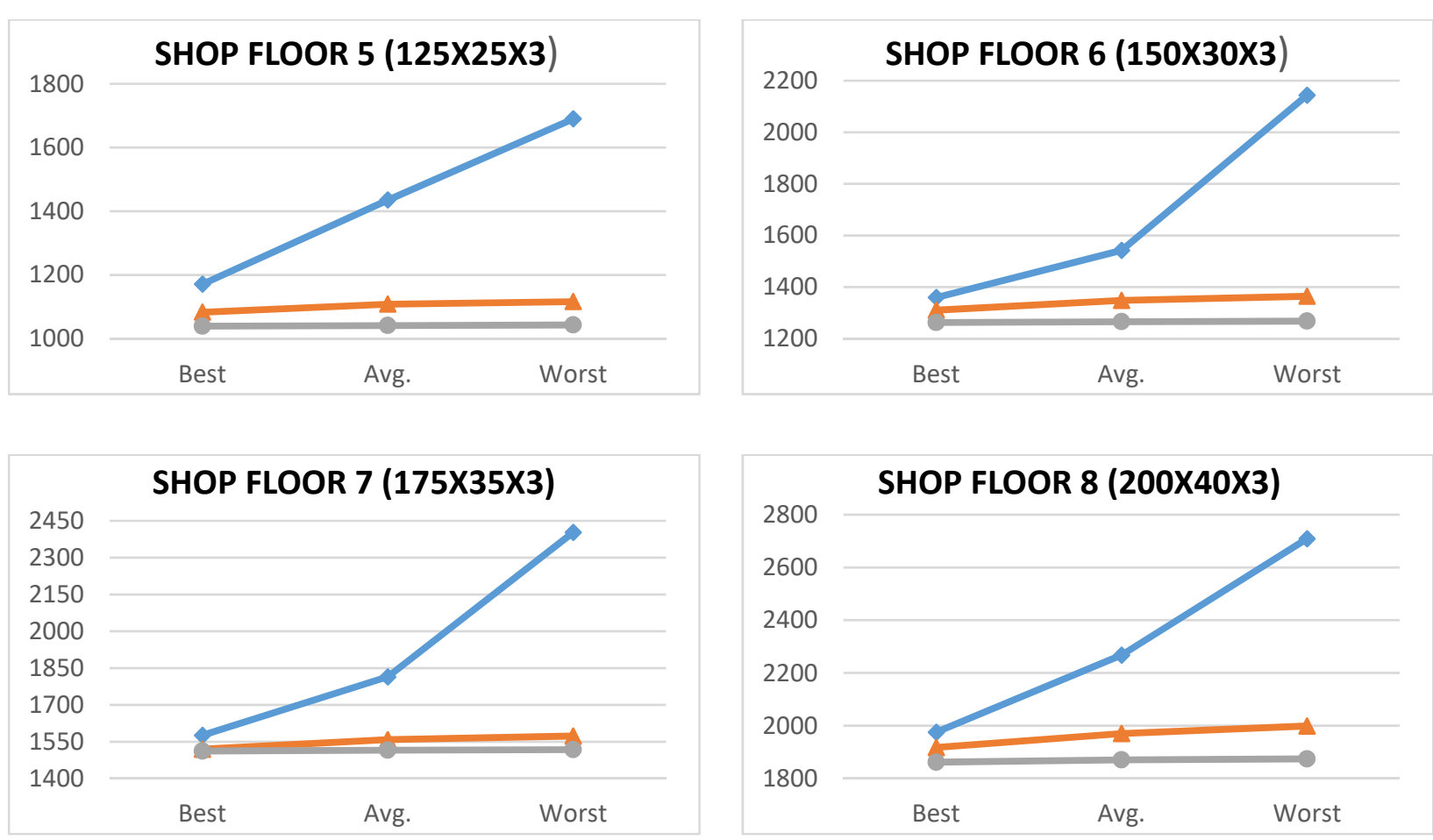

$\longrightarrow$ Ordinary $\longrightarrow$ Random

$\rightarrow$ Genetic Algorithm

Figure 2. Results of SF5, SF6, SF7 and SF8 (Comparison of Solution techniques OS, RS, GA)
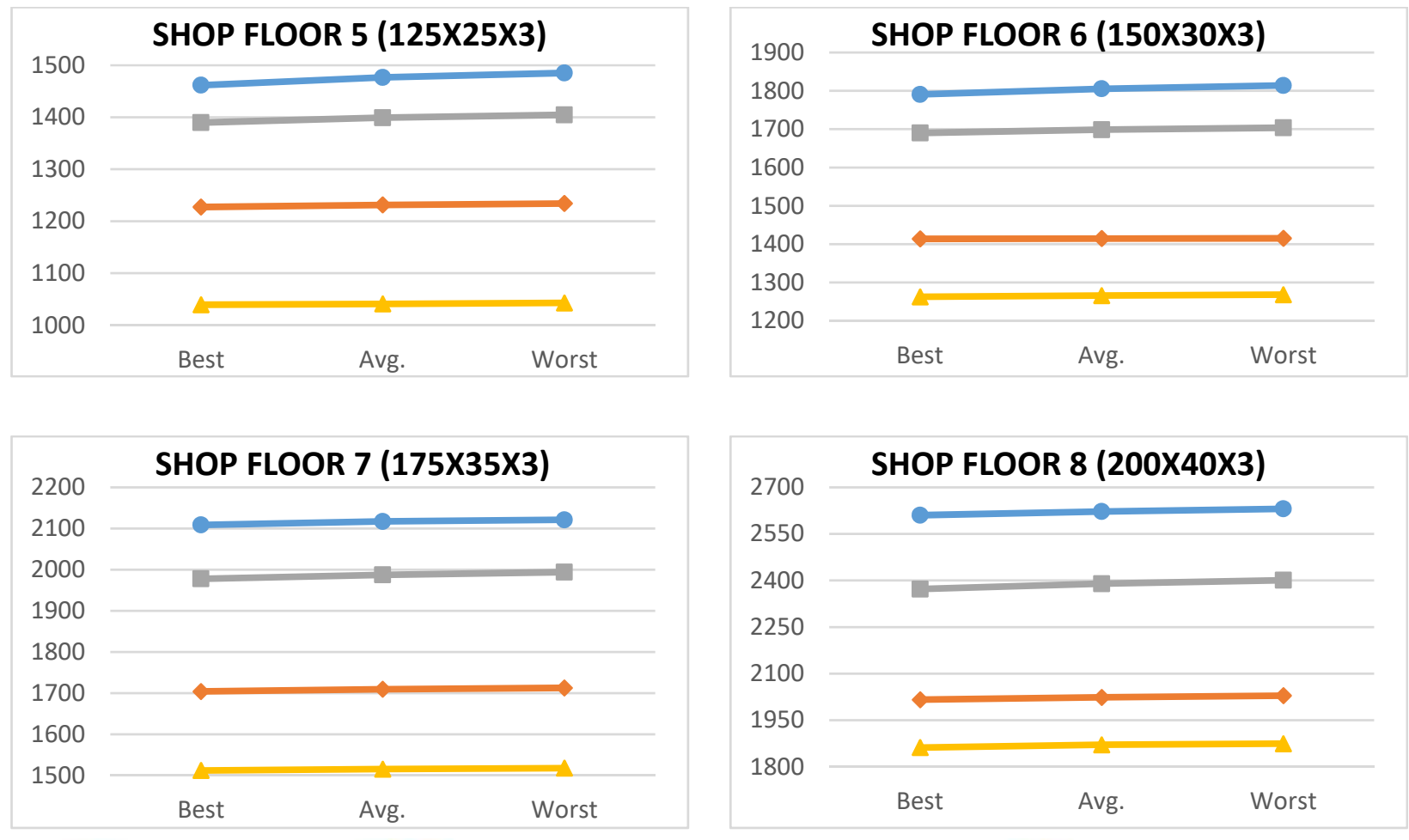

$\because$ 1-1-SIRO-RDM-genetic $\because$ 1-2-WSCH-RDM-genetic $\rightarrow$ 1-3-SIRO-WNOPPT-genetic -1 -4-WSCH-WNOPPT-genetic

Figure 3. Results of SF5, SF6, SF7 and SF8 (Comparison of integration levels according to GA) 
First four figures illustrated and summarized in Figure 2 depict how searches are superior to ordinary solutions. And they also represent directed search (GA) outperforms undirected search (RS). These results are obtained in every eight shop floors and represented for the last four larger shop floors due to limited space.

In Figure 3 again last four larger shop floors are represented and similar results are obtained in any of the eight shop floors. According to Figure 3, it can be seen that WSCH-WNOPPT level that is the fully integrated level gives always the best solution. Second best level is obtained where weighted scheduling is integrated with process planning. This level is represented as WSCHRDM and at this level, due dates are determined randomly. Third best level is found where due date assignment is integrated with process plan selection but here jobs are scheduled using SIRO rule. This level is SIRO-WNOPPT level. The final level is the totally unintegrated level. In this level, jobs are scheduled using SIRO and due dates are assigned randomly using RDM rule. As it can be seen from Figure 3, lowest level of integration is always found as the worst level and the fully integrated level is found always as the best level of integration.

\section{Conclusion}

With this study, we tried to integrate process planning, weighted scheduling and WNOPPT weighted due-date assignment. We tested different levels of integration and different search techniques.

At first, we tested unintegrated combination. We solved the problem for SIRO-RDM (OS, RS, GA). Here we assumed that scheduling is unintegrated and we used SIRO (Service in random order) dispatching. We also assumed due-date determination is unintegrated and we used RDM (Random) due-date assignment in place of exogenous, unintegrated due-date determination.

After that, we integrated WNOPPT due date assignment with process plan selection. Scheduling is performed randomly and we used SIRO dispatching. We tested here SIRO-WNOPPT (OS, RS, GA).

Finally, we integrated three functions (process planning, weighed scheduling and weighted due-date assignment). In solution (chromosome), at scheduling gene, we used 21 dispatching rules and at due-date assignment gene, we used WNOPPT. Here we solved the problem for WSCH-WNOPPT (OS, RS, GA). At the genetic search, we repeated genetic iterations up to 200 , 150, 100 and 50 iterations for eight shop floors. At Random search, we applied these many random iterations for eight different shop floors. Totally these twelve types of solutions and their explanations are given in section 5 . In Table 5 only nine types of solutions are summarized because of limited space and similar observation is obtained at every level of integration.

We have shown that integration improves global performance and as integration level increases solutions become better. If we perform each function sequentially and separately then they all try to get local optima and they don't care about the global optima. The output of process planning is an input to the scheduling. If process plans are made independently then process planner may select some machines repeatedly and some machines rarely. This may cause unbalanced machine load at shop floor and poor process plans may not be followed on the shop floor. If due dates are assigned independently from process plans and scheduling, then poor dates can be given that might give an unnecessarily long due date, unnecessarily more earliness or we might be faced with unrealistically close due dates and unnecessarily high tardiness. If we give dates without being aware of the importance of customers then the sum of weighted due date, earliness and tardiness which is performance measure can be much higher than better results that we can find. So it is better to integrate all functions and while assigning due dates and scheduling we should take into account importance of customers.

In short, integration level improves solution performance. So we should use highest integration level. Using weights while determining due dates and scheduling greatly effects weighted overall performance so we should take into account importance of customers. Finally directed search outperforms undirected search and ordinary solutions are the poorest.

\section{References}

Adamopoulos, G.I., Pappis, C.P., 1998. Scheduling under a common due-data on parallel unrelated machines. Eur. J. Oper. Res. 105, 494-501. https://doi.org/10.1016/S0377-2217(97)00057-X

Amin-Naseri, M.R., Afshari, A.J., 2012. A hybrid genetic algorithm for integrated process planning and scheduling problem with precedence constraints. Int. J. Adv. Manuf. Technol. 59, 273287.

Biskup, D., Jahnke, H., 2001. Common due date assignment for scheduling on a single machine with jointly reducible processing times. Int. J. Prod. Econ. 69, 317-322. https://doi.org/10.1016/S0925-5273(00)00040-2

Brandimarte, P., 1999. Exploiting process plan flexibility in production scheduling: A multiobjective approach. Eur. J. Oper. Res. 114, 59-71. https://doi.org/10.1016/S0377-2217(98)00029-0

Ceven, E., Demir, H.I., 2007. Benefits of Integrating Due-Date Assignment with Process Planning and Scheduling (Master of Science Thesis). Sakarya University.

Chen, Q.M., Khoshnevis, B., 1993. Scheduling with flexible process plans. Prod. Plan. Control 4, 333343. https://doi.org/10.1080/09537289308919455

Cheng, T.C.E., Chen, Z.-L., Shakhlevich, N.V., 2002. Common due date assignment and scheduling with ready times. Comput. Oper. Res. 29, 1957- 
1967. 0548(01)00067-3

https://doi.org/10.1016/S0305-

Cheng, T.C.E., Kovalyov, M.Y., 1999. Complexity of parallel machine scheduling with processingplus-wait due dates to minimize maximum absolute lateness. Eur. J. Oper. Res. 114, 403410 . https://doi.org/10.1016/S03772217(98)00111-8

Demir, H.I., Taskin, H., 2005. Integrated Process Planning, Scheduling and Due-Date Assignment (PhD Thesis). Sakarya University.

Demir, H.I., Taskin, H., Cakar, T., 2004. Integrated process planning, scheduling and due-date assignment. Presented at the International Intelligent Manufacturing Systems, Sakarya, Turkey, pp. 1165-1175.

Demir, H.I., Uygun, O., Cil, I., Ipek, M., Sari, M., 2015. Process Planning and Scheduling with SLK DueDate Assignment where Earliness, Tardiness and Due-Dates are Punished. J. Ind. Intell. Inf. 3, 173180. https://doi.org/10.12720/jiii.3.3.173-180

Gordon, V., Kubiak, W., 1998. Single machine scheduling with release and due date assignment to minimize the weighted number of late jobs. Inf. Process. Lett. 68, 153-159. https://doi.org/10.1016/S0020-0190(98)00153-7

Gordon, V., Proth, J.-M., Chu, C., 2002. A survey of the state-of-the-art of common due date assignment and scheduling research. Eur. J. Oper. Res. 139, 1-25. https://doi.org/10.1016/S03772217(01)00181-3

Gordon, V.S., Strusevich, V.A., 2009. Single machine scheduling and due date assignment with positionally dependent processing times. Eur. J. Oper. Res. 198, 57-62. https://doi.org/10.1016/j.ejor.2008.07.044

Guo, Y.W., Li, W.D., Mileham, A.R., Owen, G.W., 2009. Optimisation of integrated process planning and scheduling using a particle swarm optimisation approach. Int. J. Prod. Res. 47, 3775-3796.

Hutchison, J., Leong, K., Snyder, D., Ward, P., 1991. Scheduling approaches for random job shop flexible manufacturing systems. Int. J. Prod. Res. 29 , 1053-1067. https://doi.org/10.1080/00207549108930119

Khoshnevis, B., Chen, Q.M., 1991. Integration of process planning and scheduling functions. J. Intell. Manuf. 2, 165-175. https://doi.org/10.1007/BF01471363

Kim, K.-H., Egbelu, P.J., 1999. Scheduling in a production environment with multiple process plans per job. Int. J. Prod. Res. 37, 2725-2753. https://doi.org/10.1080/002075499190491

Kim, Y.K., Park, K., Ko, J., 2003. A symbiotic evolutionary algorithm for the integration of process planning and job shop scheduling. Comput. Oper. Res. 30, 1151-1171. https://doi.org/10.1016/S0305-0548(02)00063-1
Kumar, M., Rajotia, S., 2005. Integration of process planning and scheduling in a job shop environment. Int. J. Adv. Manuf. Technol. 28, 109-116. https://doi.org/10.1007/s00170-0042317-y

Lauff, V., Werner, F., 2004. Scheduling with common due date, earliness and tardiness penalties for multimachine problems: A survey. Math. Comput. Model. 40, 637-655. https://doi.org/10.1016/j.mcm.2003.05.019

Leung, C.W., Wong, T.N., Mak, K.L., Fung, R.Y.K., 2010. Integrated process planning and scheduling by an agent-based ant colony optimization. Comput. Ind. Eng. 59, 166-180. https://doi.org/10.1016/j.cie.2009.09.003

Li, J., Yuan, X., Lee, E.S., Xu, D., 2011. Setting due dates to minimize the total weighted possibilistic mean value of the weighted earliness-tardiness costs on a single machine. Comput. Math. Appl. 62 , 4126-4139. https://doi.org/10.1016/j.camwa.2011.09.063

Li, X., Gao, L., Zhang, C., Shao, X., 2010. A review on Integrated Process Planning and Scheduling. Int. J. Manuf. Res. 5, 161-180. https://doi.org/10.1504/IJMR.2010.03163

Lim, M.K., Zhang, D.Z., 2004. An integrated agentbased approach for responsive control of manufacturing resources. Comput. Ind. Eng., Special Issue on Selected Papers from the 27th. International Conference on Computers and Industrial Engineering, Part 1. 46, 221-232. https://doi.org/10.1016/j.cie.2003.12.006

Moon, C., Lee, Y.H., Jeong, C.S., Yun, Y., 2008. Integrated process planning and scheduling in a supply chain. Comput. Ind. Eng. 54, 1048-1061. https://doi.org/10.1016/j.cie.2007.06.018

Morad, N., Zalzala, A., 1999. Genetic algorithms in integrated process planning and scheduling. J. Intell. Manuf. 10, 169-179. https://doi.org/10.1023/A:1008976720878

Nearchou, A.C., 2008. A differential evolution approach for the common due date early/tardy job scheduling problem. Comput. Oper. Res. 35, 1329-1343. https://doi.org/10.1016/j.cor.2006.08.013

Panwalkar, S.S., Smith, M.L., Seidmann, A., 1982. Common Due Date Assignment to Minimize Total Penalty for the One Machine Scheduling Problem. Oper. Res. 30, 391-399. https://doi.org/10.1287/opre.30.2.391

Phanden, R.K., Jain, A., Verma, R., 2011. Integration of process planning and scheduling: a state-of-theart review. Int. J. Comput. Integr. Manuf. 24, 517534. https://doi.org/10.1080/0951192X.2011.562543

Tan, W., Khoshnevis, B., 2004. A linearized polynomial mixed integer programming model for the integration of process planning and scheduling. J. Intell. Manuf. 15, 593-605. 
https://doi.org/10.1023/B:JIMS.0000037710.808 47.b6

Tan, W., Khoshnevis, B., 2000. Integration of process planning and scheduling - a review. J. Intell. Manuf. 11, 51-63. https://doi.org/10.1023/A:1008952024606

Usher, J.M., 2003. Evaluating the impact of alternative plans on manufacturing performance. Comput. Ind. Eng. 45, 585-596. https://doi.org/10.1016/S0360-8352(03)00076-7

Xia, Y., Chen, B., Yue, J., 2008. Job sequencing and due date assignment in a single machine shop with uncertain processing times. Eur. J. Oper. Res. 184 ,

63-75. https://doi.org/10.1016/j.ejor.2006.10.058

Ying, K.-C., 2008. Minimizing earliness-tardiness penalties for common due date single-machine scheduling problems by a recovering beam search algorithm. Comput. Ind. Eng. 55, 494-502. https://doi.org/10.1016/j.cie.2008.01.008

Zhang, H.-C., Mallur, S., 1994. An integrated model of process planning and production scheduling. Int. J. Comput. Integr. Manuf. 7, 356-364. https://doi.org/10.1080/09511929408944623 